\title{
A novel index for quantifying the risk of early complications for patients undergoing cervical spine surgeries
}

\author{
Peter G. Passias, MD, ${ }^{1}$ Bassel G. Diebo, MD, ${ }^{2}$ Bryan J. Marascalchi, MD, ${ }^{4}$ Cyrus M. Jalai, BA, ${ }^{1}$ \\ Samantha R. Horn, BA, ${ }^{1}$ Peter L. Zhou, BA, ${ }^{1}$ Karen Paltoo, BA, ${ }^{2}$ Olivia J. Bono, BA, ${ }^{1}$ \\ Nancy Worley, BA, ${ }^{1}$ Gregory W. Poorman, BA, ${ }^{1}$ Vincent Challier, MD, ${ }^{5}$ Anant Dixit, MD, ${ }^{2}$ \\ Carl Paulino, MD, ${ }^{2}$ and Virginie Lafage, $\mathrm{PhD}^{3}$
}

${ }^{1}$ Division of Spine Surgery, Department of Neurological and Orthopaedic Surgery, NYU Langone Medical Center, New York; 2Department of Orthopaedic Surgery, State University of New York, Downstate Medical Center, Brooklyn; ${ }^{3}$ Department of Orthopaedic Surgery, Hospital for Special Surgery, New York, New York; ${ }^{4}$ Department of Anesthesiology and Critical Care Medicine, Johns Hopkins Hospital, Baltimore, Maryland; and ${ }^{5}$ Spine Unit 1, Orthopedic Surgery Department, Bordeaux University Hospital, Bordeaux, France

OBJECTIVE It is becoming increasingly necessary for surgeons to provide evidence supporting cost-effectiveness of surgical treatment for cervical spine pathology. Anticipating surgical risk is critical in accurately evaluating the risk/benefit balance of such treatment. Determining the risk and cost-effectiveness of surgery, complications, revision procedures, and mortality rates are the most significant limitations. The purpose of this study was to determine independent risk factors for medical complications (MCs), surgical complications (SCs), revisions, and mortality rates following surgery for patients with cervical spine pathology. The most relevant risk factors were used to structure an index that will help quantify risk and anticipate failure for such procedures.

METHODS The authors of this study performed a retrospective review of the National Inpatient Sample (NIS) database for patients treated surgically for cervical spine pathology between 2001 and 2010. Multivariate models were performed to calculate the odds ratio (OR) of the independent risk factors that led to MCs and repeated for SCs, revisions, and mortality. The models controlled for age (< and > 65 years old), sex, race, revision status (except for revision analysis), surgical approach, number of levels fused/re-fused $(2-3,4-8, \geq 9)$, and osteotomy utilization. ORs were weighted based on their predictive category: 2 times for revision surgery predictors and 4 times for mortality predictors. Fifty points were distributed among the predictors based on their cumulative OR to establish a risk index.

RESULTS Discharges for 362,989 patients with cervical spine pathology were identified. The mean age was 52.65 years, and $49.47 \%$ of patients were women. Independent risk factors included medical comorbidities, surgical parameters, and demographic factors. Medical comorbidities included the following: pulmonary circulation disorder, coagulopathy, metastatic cancer, renal failure, congestive heart failure, alcohol abuse, neurological disorder, nonmetastatic cancer, liver disease, rheumatoid arthritis/collagen vascular diseases, and chronic blood loss/anemia. Surgical parameters included posterior approach to fusion/re-fusion, $\geq 9$ levels fused/re-fused, corpectomy, 4-8 levels fused/re-fused, and osteotomy; demographic variables included age $\geq 65$ years. These factors increased the risk of at least 1 of MC, SC, revision, or mortality (risk of death). A total of 50 points were distributed among the factors based on the cumulative risk ratio of every factor in proportion to the total risk ratios.

CONCLUSIONS This study proposed an index to quantify the potential risk of morbidity and mortality prior to surgical intervention for patients with cervical spine pathology. This index may be useful for surgeons in patient counseling efforts as well as for health insurance companies and future socioeconomics studies in assessing surgical risks and benefits for patients undergoing surgical treatment of the cervical spine.

https://thejns.org/doi/abs/10.3171/2017.3.SPINE16887

KEY WORDS risk index; surgical risk; cervical; spine surgery

ABBREVIATIONS ARDS = adult respiratory distress syndrome; $\mathrm{CHF}=$ congestive heart failure $; \mathrm{Cl}=$ confidence interval; $\mathrm{MC}=$ medical complication; $\mathrm{NIS}=\mathrm{National}$ Inpatient Sample; NSQIP = National Surgical Quality Improvement Program; OR = odds ratio; SC = surgical complication.

SUBMITTED July 27, 2016. ACCEPTED March 23, 2017.

INCLUDE WHEN CITING Published online August 25, 2017; DOI: 10.3171/2017.3.SPINE16887. 
$\mathrm{D}$ EGENERATIVE changes in the cervical spine are a near-universal feature of aging ${ }^{9,18}$ and are at the root of a wide spectrum of clinical presentations and sequelae. Cervical spine pathologies might include cervical radiculopathy and/or cervical myelopathy and can manifest variably, with common symptoms including neck and/or arm pain. The incidence of cervical spine pathologies has varied, depending on the specific diagnosis; cervical radiculopathy has been estimated annually at an incidence rate of 83 per 100,000 persons and cervical myelopathy rates are reported to have dramatically increased in patients over the age of 55 years. ${ }^{10,24}$

While many cervical pathologies can be managed conservatively, surgical intervention is often required for persistent and progressive symptoms. ${ }^{10,14,17,20}$ Despite established clinical and functional benefits of surgical interventions, complications associated with cervical spine surgery persist. In addition, there is a steady increase in the average national age in the US, which necessitates measures to evaluate the efficacy of treatment for cervical spine pathologies. From a clinical and cost-effectiveness standpoint, these measures retain increased value. ${ }^{26}$ Useful metrics for evaluating such features of cervical surgery remain largely unexplored, however.

Complication rates range widely based on patient characteristics and the extent of the surgical intervention; rates have been estimated from $18.5 \%$ to $51.7 \%$. Significant complications, including neurological functional changes and infections, demonstrate significant postoperative clinical impact and diminish the value of such interventions..$^{57,15}$ The need for revision surgery is also a well-documented occurrence for cervical pathologies and has been shown to be influenced by surgical approach, diagnosis, and baseline factors. ${ }^{19,25}$ The value, then, in anticipating adverse events associated with the surgical management of cervical pathology is critical in balancing the risk/benefit ratio of such a treatment course. More importantly, studies investigating predictors for poor outcomes following cervical surgery are surprisingly varied in their findings: older age, sex, diabetes, hypertension, and smoking status, for instance, have all been implicated as factors contributing to worse postoperative results. ${ }^{12,23,27}$ One risk index for the application of any surgical procedure is the National Surgical Quality Improvement Program (NSQIP) Surgical Risk Calculator. Using similarly aggregated data as the National Inpatient Sample (NIS), NSQIP uses logistic regression to divide comorbidities and demographic factors into a variety of outcome categories. Examples of these categories are "serious complication," "any complication," and "return to OR." Although these categories are not cervical specific and thus have their limitations, they serve as the basis for the model described in this paper, which is an adaptation of the same model the authors previously created for adult spinal deformity using the NIS.

This study sought to determine independent risk factors for perioperative medical complications (MCs), surgical complications (SCs), revisions, and mortality following operative treatment for cervical spine pathologies, and subsequently combine these independent risk factors to determine the collective risk of surgical intervention. We queried a nationwide database (the NIS) from 2001 to
2010 to structure relevant risk factors into a novel index to quantify the risk of cervical spine surgical procedures.

\section{Methods \\ Data Source}

The NIS (https://www.hcup-us.ahrq.gov/nisoverview. jsp) is the largest all-payer database in the US. It contains data for approximately 8 million annual discharges from approximately 1000 hospitals in 45 states, representing an approximate $20 \%$ stratified sample of community hospitals. The NIS contains 100 clinical and demographic data elements, with diagnoses and procedures presented in ICD-9-CM format. National estimates are derived from discharge weighted files. More information on the NIS design is available at http://hcup-us.ahrq.gov/db/nation/nis/ NIS_Introduction_2012.jsp.

\section{Inclusion Criteria}

Annual data files from 2001 to 2010 were collected. Included discharges were those patients 25 years of age and older with the following ICD-9-CM coding for cervical spine pathology: patients included based on procedure code were those undergoing anterior or posterior fusion of the spine (81.01-81.03, 81.31-81.33), cervical discectomy (80.51), and decompression of the spinal canal including laminoplasty (03.09). Also, by diagnosis code, patients with an open or closed cervical fracture (805.0x, 805.1, 806.1x, 839.0x, 839.0x, 839.1x), cervical spondylosis with or without myelopathy $(721.0,721.1)$, and cervical stenosis or disc degeneration $(723.0,722.4)$ were included. Cervical fusion or re-fusion lengths were categorized as $2-3$, $4-8$ or $\geq 9$ levels (81.62-81.64). An anterior fusion (81.02 and 81.32) and posterior fusion (81.03 and 81.33) approach was stratified. Exclusion criteria included patients with any metastatic or nonmetastatic cancer, lymphoma, or leukemia (140.x-172x, 174.x-195.8x, 200.x-208.x, 196.x199.1). The laminoplasty cohort excluded any fusions, re-fusions, bone morphogenetic protein usage, fusion devices, or corpectomies $(81.00-81.09,81.30-81.39,84.52$, or 80.99). The combined anterior and posterior cohort excluded lumbar fusions or re-fusions $(81.06,81.08,81.36$, 81.38). Additionally, the anterior cervical discectomy and fusion cohort excluded posterior and lumbar fusions or refusions $(81.03,81.33,81.06-81.08$, and 81.36-81.38). The posterior fusion cohort excluded anterior and lumbar fusions or re-fusions (81.06-81.08 and 81.36-81.38).

\section{Data Collection}

Demographic data for patient age, sex, race, mortality, comorbidity status, expected primary payer, total charges, length of hospital stay, and discharge/admission type were collected. Surgical factors collected included approach, number of levels fused/re-fused, osteotomy usage (77.39, 77.29), and revision status. Procedure-related complications resulting from surgical and medical care were determined using ICD-9-CM codes specific for individual complications. SCs included postoperative shock, hematoma/seroma formation, puncture laceration of a nerve or vessel, wound dehiscence, postoperative infection, hemorrhagic anemia, and dural tear complications; MCs includ- 
TABLE 1. Patient- and hospital-related characteristics for all patients undergoing cervical spine surgery (2001-2010)

\begin{tabular}{|c|c|}
\hline Variable & Value (\%) \\
\hline \multicolumn{2}{|l|}{ Age } \\
\hline Overall mean yrs & 52.65 \\
\hline $18-44$ yrs & $99,988(27.55)$ \\
\hline $45-64$ yrs & $194,723(53.64)$ \\
\hline $65-74$ yrs & $45,476(12.53)$ \\
\hline $75+y r s$ & $22,802(6.28)$ \\
\hline \multicolumn{2}{|l|}{ Sex } \\
\hline Male & $183,186(50.53)$ \\
\hline Female & $179,324(49.47)$ \\
\hline \multicolumn{2}{|l|}{ Race } \\
\hline White & $221,071(81.73)$ \\
\hline Black & $24,976(9.23)$ \\
\hline Hispanic & $13,598(5.03)$ \\
\hline Asian/Pacific Islander & $3368(1.25)$ \\
\hline Native American & $1170(0.43)$ \\
\hline Other & $6304(2.33)$ \\
\hline \multicolumn{2}{|l|}{ Primary payer } \\
\hline Medicare & $86,513(23.89)$ \\
\hline Medicaid & $20,472(5.65)$ \\
\hline Private insurance & $206,257(56.97)$ \\
\hline \multicolumn{2}{|l|}{ Self-pay } \\
\hline \multicolumn{2}{|l|}{ No charge } \\
\hline \multicolumn{2}{|l|}{ Other } \\
\hline \multicolumn{2}{|l|}{ Admission type } \\
\hline Routine & $25,373(7.72)$ \\
\hline Urgent & $24,046(7.32)$ \\
\hline Elective & $276,967(84.31)$ \\
\hline Trauma center & $2081(0.63)$ \\
\hline Other & $27(0.01)$ \\
\hline \multicolumn{2}{|l|}{ Discharge type } \\
\hline Routine & $309,765(85.41)$ \\
\hline Short-term hospital & $1723(0.48)$ \\
\hline Other transfers & $31,149(8.59)$ \\
\hline $\mathrm{HHC}$ & $18,196(5.02)$ \\
\hline AMA & $270(0.07)$ \\
\hline Death & $1501(0.41)$ \\
\hline Deyo score* & 0.44 \\
\hline Mean total charges in dollars & $46,446.03$ \\
\hline Mean LOS in days & 3.14 \\
\hline Mortality & $1501(0.41)$ \\
\hline
\end{tabular}

AMA = against medical advice; $\mathrm{HHC}=$ home health care; $\mathrm{LOS}=$ length of hospital stay.

* From Schneeweiss S, Wang PS, Avorn J, et al: Consistency of performance ranking of comorbidity adjustment scores in Canadian and U.S. utilization data. J Gen Intern Med 19:444-450, 2004

ed CNS, cardiac, peripheral vascular, respiratory, gastrointestinal, genitourinary, and venous thrombotic events as well as adult respiratory distress syndrome (ARDS).

\section{Statistical Analysis}

Statistical analysis was performed using $\mathrm{R}$ ( $\mathrm{R}$ Foundation for Statistical Computing). All calculated and reported statistics were weighted to provide nationwide estimates using the NIS-provided weight files. Four multivariate
TABLE 2. Baseline patient comorbidities for all patients undergoing cervical spine surgery (2001-2010)

\begin{tabular}{lrr}
\hline \multicolumn{1}{c}{ Comorbidity } & $\begin{array}{c}\text { No. of } \\
\text { Patients }\end{array}$ & \multicolumn{1}{c}{$\%$} \\
\hline Smoking history & 67,904 & 18.71 \\
\hline Chronic pulmonary disease & 47,274 & 13.02 \\
\hline Obesity & 22,757 & 6.27 \\
\hline Anemia (deficiency) & 10,306 & 2.84 \\
\hline Neurological disorders & 10,271 & 2.83 \\
\hline Rheumatoid arthritis/collagen vascular diseases & 8382 & 2.31 \\
\hline Cardiac valvular disorders & 8350 & 2.30 \\
\hline Alcohol abuse & 6555 & 1.81 \\
\hline CHF & 5166 & 1.43 \\
\hline Renal failure & 4215 & 1.16 \\
\hline Peripheral vascular disorders & 4139 & 1.14 \\
\hline Illicit drug usage & 3597 & 0.99 \\
\hline Coagulopathy & 2688 & 0.74 \\
\hline Liver disease & 2688 & 0.74 \\
\hline Tumor & 2346 & 0.65 \\
\hline Metastasis & 2163 & 0.60 \\
\hline Pulmonary circulation disorders & 1205 & 0.33 \\
\hline Chronic blood loss/anemia & 669 & 0.18 \\
\hline
\end{tabular}

models were generated to identify the independent risk factors for experiencing an $\mathrm{MC}, \mathrm{SC}$, revision surgery, or death. Each model controlled for age ( $<$ and $>65$ years old), sex, race, revision status (except for the revision analysis), surgical approach, number of levels fused/re-fused (2-3, $4-8, \geq 9$ ), and osteotomy utilization. Odds ratios (ORs) for each identified factor were included in the novel index both if they were statistically significant $(p<0.05)$ and clinically relevant $(\mathrm{OR}<1.5)$ to ensure clinical impact and to avoid borderline factors. ${ }^{11}$ Cumulative ORs were weighted based on their predictive category to generate a novel index according to the following equation: $(1 \times \mathrm{MC})+(1 \times$ $\mathrm{SC})+(2 \times$ revision $)+(4 \times$ mortality $)$. Fifty points were then distributed among the identified predictors based on their cumulative ORs and ranked to establish the novel risk index. Three risk thresholds were proposed: mild (0-10), moderate (10-20), and severe ( $>20-50$ points).

\section{Results \\ Patient Demographics}

There were 362,989 cervical pathology discharges identified from 2001 to 2010. Patient- and hospital-related characteristics for the total cohort are summarized in Table 1 . The mean patient age was 52.65 years, with most patients in the 45-64 age range (53.64\%) and comprising 183,186 males $(50.53 \%)$. Patients were predominantly white $(81.73 \%)$ and were insured by private insurance (56.97\%) and Medicare (23.89\%). The average length of hospital stay was 3.14 days, and the mean cost of hospital charges was $\$ 46,446.03$. There were 92,255 patients with cervical myelopathy (25.42\%), and 7162 (1.98\%) had scoliosis. The most frequent comorbidities (Table 2) among 
the patients with cervical spine pathology were a history of smoking ( $\mathrm{n}=67,904 ; 18.71 \%)$, chronic pulmonary disease $(n=47,274 ; 13.02 \%)$, and obesity $(n=22,757 ; 6.27 \%)$.

\section{Surgical Summary}

Overall, $3.54 \%$ of patients underwent corpectomies and $0.08 \%$ underwent osteotomies. The overall complication rate for all cervical patients in this study was $8.14 \%$. The most frequently experienced complications were device related (2.67\%), ARDS (1.51\%), and acute posthemorrhagic anemia (1.38\%; Table 3$)$.

\section{Independent Risk Factors}

Multivariate analysis of presenting patient comorbidities and procedure-related variables identified the following factors as significant independent risk factors for increasing MC, SC, revision, and/or mortality (Table 4): pulmonary circulation disorders, coagulopathy, posterior fusion/re-fusion, metastatic cancer, renal failure, age $\geq 65$ years, congestive heart failure (CHF), $\geq 9$ levels fused/refused, corpectomy, alcohol abuse, neurological disorder, nonmetastatic cancer, liver disease, rheumatoid arthritis, 4-8 levels fused/re-fused, osteotomy utilization, and chronic blood loss/anemia. Overall, among the identified baseline comorbidities, pulmonary circulation disorders had the greatest impact, increasing MCs (OR 16.14) and mortality (risk of death; OR 8.53). Among the considered surgical factors, $\geq 9$ levels fused had the most effect, as it increased the odds of both MCs (OR 3.88) and SCs (OR 5.61) the most.

\section{Medical Complications}

The model for MCs revealed that pulmonary circulation disorders had the greatest risk of sustaining an MC (OR 16.14, 95\% confidence interval [CI] 14.53-17.93). These odds are far greater than the next two highest risk factors combined: $\geq$ 9-level fusion (OR 3.88, 95\% CI 3.39-4.45) and blood loss (OR 3.23, 95\% CI 2.67-3.90). Nevertheless, the surgical factor that most increased the MC odds was $\geq 9$-level fusion (OR 3.88, 95\% CI 3.39-4.45). This is in contrast to 4- to 8-level fusion, which increased the $\mathrm{MC}$ odds to a lesser degree (OR 1.76, 95\% CI 1.70-1.83). Other surgical variables that increased the risk of MCs were posterior approach (OR 1.74, 95\% CI 1.67-1.82) and the utilization of corpectomy (OR 1.68, 95\% CI 1.58-1.77). All $\mathrm{p}$ values were $<0.05$.

\section{Surgical Complications}

The model for SCs showed that patients who had $\geq$ 9-level fusion had the greatest risk of sustaining SCs (OR 5.61, 95\% CI 4.93-6.39). Consequently, fewer levels of fusion had a smaller impact on the odds of complication, i.e., 4- to 8-level fusion (OR 2.18, 95\% CI 2.10-2.27). However, the comorbidity that most increased SC odds was coagulopathy (OR 3.92, 95\% CI 3.55-4.33). Unlike what was observed with MCs, pulmonary circulation disorders increased the SC odds to a smaller extent (OR 2.05, 95\% CI 1.74-2.30) compared with coagulopathy. Other independent predictors of SCs included revision surgery (OR 1.71, 95\% CI 1.58-1.86); metastases (OR 1.58, 95\% CI
TABLE 3. Organ-specific and other complication rates for all patients undergoing cervical spine surgery (2001-2010)

\begin{tabular}{lcc}
\hline \multicolumn{1}{c}{ Variable } & No. of Patients & $\%$ \\
\hline Organ-specific complications & & \\
\hline Respiratory & 1915 & 0.53 \\
\hline Urinary & 1723 & 0.47 \\
\hline Cardiac & 1582 & 0.44 \\
\hline Nervous system & 1346 & 0.37 \\
\hline Digestive system & 1158 & 0.32 \\
\hline Peripheral vascular & 114 & 0.03 \\
\hline Other complications of procedures & & \\
\hline Device-related & 9676 & 2.67 \\
\hline ARDS & 5467 & 1.51 \\
\hline Acute posthemorrhagic anemia & 4992 & 1.38 \\
\hline Hematoma/seroma & 1967 & 0.54 \\
\hline Puncture vessel/nerve & 1699 & 0.47 \\
\hline Venous thrombotic events & 1293 & 0.36 \\
\hline Postop infection & 811 & 0.22 \\
\hline Pulmonary embolism & 572 & 0.16 \\
\hline Dural tear & 519 & 0.14 \\
\hline Wound dehiscence & 302 & 0.08 \\
\hline Postop shock & 76 & 0.02 \\
\hline
\end{tabular}

$1.35-1.85)$ and $\geq 65$ years of age (OR $1.58,95 \%$ CI 1.52 $1.65)$ had the smallest impact. All $\mathrm{p}$ values were $<0.05$.

\section{Revision Model}

The model for revision risk included only surgical factors. Of these surgical factors, a posterior approach elevated the revision odds the most (OR 4.33, 95\% CI 4.184.48). In contrast, corpectomy had the smallest impact of the considered factors (OR 1.61, 95\% CI 1.52-1.71). Additionally, fusion of $\geq 9$ levels also had a significant effect on revision risk (OR 2.63, 95\% CI 2.27-3.04). Fusion of 4-8 levels also had an effect, although smaller than $\geq 9$ levels (OR 1.66, 95\% CI 1.60-1.72). Of note, diagnosis of cervical myelopathy was a significant predictor of decreased revision rate (OR $0.41,95 \%$ CI $0.39-0.42)$. All $\mathrm{p}$ values were $<0.05$.

\section{Mortality Model}

Pulmonary circulation disorders increased the risk of death the most (OR 8.53, 95\% CI 6.96-10.44; Table 4). Among the considered factors, black race had the least impact on mortality odds (OR $1.56,95 \%$ CI $1.36-1.79$ ). The surgical factor that most increased the risk of death was a posterior approach (OR 2.10, 95\% CI 1.87-2.05). Although fusions of $\geq 9$ levels had a significant impact on surgical complications, it did not have a significant effect on the mortality model (OR 1.14, 95\% CI 0.76-1.71). Interestingly, fusions of 4-8 levels had a greater increase in risk of death (OR 1.38, 95\% CI 1.24-1.54) compared with $\geq 9$ levels. However, the increased odds from 4- to 8-level fusions was not included because the OR was $<1.5$. All $\mathrm{p}$ values were $<0.05$. 
TABLE 4. Scoring method of the risk index for surgical treatment of patients with cervical spine pathology

\begin{tabular}{|c|c|c|c|c|c|}
\hline \multirow[b]{2}{*}{ Risk Factor } & \multicolumn{4}{|c|}{ Individual OR } & \multirow{2}{*}{$\begin{array}{c}\text { Cumulative } \\
\text { OR* }\end{array}$} \\
\hline & MC & SC & Revision & Mortality & \\
\hline $\begin{array}{l}\text { Pulmonary circulation } \\
\text { disorder }\end{array}$ & 16.14 & 2.05 & NS & 8.53 & 52.29 \\
\hline Coagulopathy & 3.12 & 3.92 & NS & 5.34 & 28.40 \\
\hline $\begin{array}{l}\text { Posterior approach to } \\
\text { fusion/re-fusion }\end{array}$ & 1.74 & 2.23 & 4.33 & 2.10 & 21.03 \\
\hline Metastatic cancer & 1.50 & 1.58 & NS & 3.92 & 18.76 \\
\hline Renal failure & NS & 1.86 & NS & 4.12 & 18.34 \\
\hline Age $\geq 65$ yrs & 1.67 & 1.58 & NS & 3.44 & 17.02 \\
\hline $\mathrm{CHF}$ & 2.62 & NS & NS & 3.27 & 15.69 \\
\hline $\begin{array}{l}\geq 9 \text { levels fused/re- } \\
\text { fused }\end{array}$ & 3.88 & 5.61 & 2.63 & NS & 14.75 \\
\hline Corpectomy & 1.68 & 2.07 & 1.61 & 1.75 & 13.97 \\
\hline Alcohol abuse & 2.20 & 1.94 & NS & 2.18 & 12.87 \\
\hline Neurological disorder & NS & NS & NS & 2.30 & 9.20 \\
\hline Nonmetastatic cancer & NS & NS & NS & 1.91 & 7.64 \\
\hline Liver disease & NS & NS & NS & 1.85 & 7.40 \\
\hline Rheumatoid arthritis & NS & NS & NS & 1.82 & 7.30 \\
\hline $\begin{array}{l}\text { 4-8 levels fused/re- } \\
\text { fused }\end{array}$ & 1.76 & 2.18 & 1.66 & NS & 7.27 \\
\hline Osteotomy & NS & 2.77 & 1.83 & NS & 6.43 \\
\hline $\begin{array}{l}\text { Chronic blood loss/ } \\
\text { anemia }\end{array}$ & 3.23 & NS & NS & NS & 3.23 \\
\hline Total & & & & & 261.59 \\
\hline
\end{tabular}

NS = nonsignificant, or OR $<1.5$.

* Cumulative OR calculated as: $(1 \times \mathrm{MC})+(1 \times \mathrm{SC})+(2 \times$ revision $)+(4 \times$ mortality).

\section{Structured Risk Index}

Table 5 presents the cumulative ORs for the significant identified risk factors in the structured index. Based on the weighted OR, 50 points were distributed across the index. Notably, pulmonary circulation disorders, such as primary pulmonary hypertension or pulmonary embolism, received the highest rank with 10 points. Pulmonary circulation disorders were followed by coagulopathy, which includes diseases such as hemophilia and von Willebrand's disease (5 points). The surgical factor with the highest rank was the posterior approach with 4 points. Metastases also received a ranking of 4 points. The other risk factors were given lower ratings up to 1 point. Overall, surgeons can use this model by adding points for each risk factor and the additive model will place a patient into a surgical risk category.

\section{Case Vignette}

As an example of how to use the index, a 75-yearold male patient with a history of rheumatoid arthritis is scheduled to undergo 5-level, posterior cervical fusion. To quantify the risk associated with this surgery, the patient can be scored based on our proposed structured index as follows: 3 points for $>65$ years of age, 1 point for history of rheumatoid arthritis, 1 point for $>$ 4-level fusion, and
TABLE 5. Structured index for cervical spine surgical risk, based on cumulative ORs

\begin{tabular}{lcc}
\hline \multicolumn{1}{c}{ Comorbidity } & Cumulative OR & Index Score \\
\hline Pulmonary circulation disorder & 52.29 & 10 \\
\hline Coagulopathy & 28.40 & 5 \\
\hline Posterior approach to fusion/re-fusion & 21.03 & 4 \\
\hline Metastatic cancer & 18.76 & 4 \\
\hline Renal failure & 18.34 & 4 \\
\hline Age $\geq 65$ yrs & 17.02 & 3 \\
\hline CHF & 15.69 & 3 \\
\hline$\geq 9$ levels fused/re-fused & 14.75 & 3 \\
\hline Corpectomy & 13.97 & 3 \\
\hline Alcohol abuse & 12.87 & 2 \\
\hline Neurological disorder & 9.20 & 2 \\
\hline Nonmetastatic cancer & 7.64 & 2 \\
\hline Liver disease & 7.40 & 1 \\
\hline Rheumatoid arthritis & 7.30 & 1 \\
\hline 4-8 levels fused/re-fused & 7.27 & 1 \\
\hline Osteotomy & 6.43 & 1 \\
\hline Chronic blood loss/anemia & 3.23 & 1 \\
\hline Total & 261.59 & 50 \\
\hline
\end{tabular}

4 points for the posterior approach. The total number of points is 9 of 50, which is a mild risk.

\section{Discussion}

Quantification of surgical risk for cervical spine surgeries is important for the betterment of patient care. While risk assessment is a commonly studied subject, according to the literature, no indices have been developed for the unique surgical considerations associated with cervical spine pathologies. Most literature describes the impact of individual complications on spine surgeries. Comprehensive risk indices, which use patient demographics, surgical procedures, and patient comorbidities, allow for the ascertainment of the probability of adverse events as well as their impact on patients. This helps clinicians to clearly predict the relative impact of patient-specific characteristics and surgical variables on perioperative patient outcomes while allowing them to better gauge benefits and risks for individual patients. This study aimed to develop a comprehensive risk index specific to surgical interventions in the cervical spine.

Overall, pulmonary circulation disorders had the highest associated risk-impact score of any other input variable. This finding is consistent with other studies evaluating the surgical management of spinal disorders. For example, Worley et al. found that pulmonary disorders were associated with the highest OR for increasing morbidity and mortality following surgical correction of adult spinal deformities. ${ }^{27}$ Following pulmonary disorders, coagulopathy had the next highest risk score. This high risk-impact score may stem from the fact that perioperative hemostatic dysfunction can be multifactorial in nature, resulting from a variety of physiological imbalances. ${ }^{13}$ Our findings agree 
with previous studies that have also shown coagulopathy to be an independent risk factor for perioperative mortality. ${ }^{16}$ Another particularly at-risk group of patients were those undergoing cervical fusion by a posterior approach. These patients commonly undergo longer and more aggressive surgeries due to revision constructs. These revision constructs are performed to support the increased degeneration and instability that may have resulted from the previous fusion or laminectomy. ${ }^{4}$ Literature can be found showing the deleterious effect of revision status on spine surgery outcomes. For instance, Diebo et al. found that the frequency of procedure-related complications was increased for patients who underwent revision compared with those who did not. ${ }^{3}$

Smoking, contrary to expectations, did not reach the threshold of inclusion in the final model and thus was not included. This may indicate that the well-established negative impact of smoking on orthopedic outcomes may be limited to longer-term outcomes, as this study focused on inpatient outcomes. Likewise, anemia is a relatively common finding before elective spine surgery, and is usually treated with perioperative blood transfusions. ${ }^{2}$ Our findings indicate that deficiency-related anemia was also not associated with an OR $>1.5$ in the incidence of complications, while chronic anemia is. This may, in part, be due to an underlying pathology for those with anemia of chronic disease. The relationship between these comorbidities and elective spine surgery remains unclear and calls for further investigation.

Chronic obstructive pulmonary disease was defined as chronic bronchitis (ICD-9 codes 490-491), emphysema (492), asthma (493), bronchiectasis (494), hypersensitivity pneumonitis (495), or chronic airway obstruction (496). With an incidence of $13.02 \%$ in our cohort of 8 million, this patient population most likely consisted of many patients with milder conditions such as asthma, which has contributed an estimated $7.4 \%-10.8 \%$ to the incidence in the population. ${ }^{1}$ Controlled asthma is not associated with increased risk for intra- or perioperative complications, but airway-associated complications are associated with the most deaths in spine surgeries. ${ }^{22}$ Other inputs including obesity, peripheral vascular disease, cardiac valvular disease, and illicit drug use were not associated with an OR of 1.5 or greater and were excluded from the risk index; their adverse effects on outcomes were to a lesser degree than those factors included.

This paper attempts to characterize how the presence of comorbidities interacts with surgical conditions to increase the relative risk of cervical procedures. For example, surgical metrics of osteotomy and fusions of 4-8 levels ranked low in the index, only contributing 1 point each. This indicates that, after controlling for all other comorbidities and surgical indications, these advanced surgeries are being completed with minimal additional risk and no additional mortality. Similarly, fusions of more than 9 levels contributed significantly to the risk index with 3 points, which by itself is a mild risk. However, if these fusions were performed in an elderly patient (age $\geq 65$ years) with renal failure, the risk index would increase to 11 points, a high-risk procedure.

To our knowledge this study is unique in its combi- nation of such an expansive representation of patient comorbidities and their impact on an equally wide scope of complications. Our risk index is externally consistent with complication and comorbidity rates found in other population-based studies and randomized controlled trials. Risks of complications in dedicated studies also report similar results to our outcomes. For example, Skolasky et al. found a mortality rate of $0.42 \%$, as well as a complication rate of $4.09 \%$, compared with our respective rates of $0.42 \%$ for both. ${ }^{21}$ This allows caregivers to analyze comorbidities in combination where the impact of multiple comorbidities may be obscure.

Risk indices commonly assess a scalar representation of the minimum to maximum possible impact of an occurrence of a risk. Next, a composite risk index assesses how likely this event is to happen. The current model thoroughly develops the likelihood of complication events occurring through use of a database containing 8 million patients per year. However, the impact of each risk was assigned depending on expert opinion, based on the impact on hospital costs and patient outcomes. Expert surgical opinion has been shown to not always align with patient and payer perspectives. ${ }^{8}$

We acknowledge there are inherent limitations to our cumulative index, and that further evaluation is necessary. The next step in validating this risk index would be to compare outcome measures to patient-reported outcomes and costs. Also, to complete this risk index, it is necessary to consider alleviating effects of healthy patients and less invasive procedures with shorter operative times. Another limit of this study is the usage of a national database such as the NIS, which may not be as precise and focused on our measured outcome variables. Additionally, there are no sustained follow-up or patient-reported outcomes, which limits the scope of our index to comorbidities and intraoperative and perioperative outcomes. The NIS also does not have information on the magnitude of a patient's morbidity.

\section{Conclusions}

This study developed an index to score surgeries based on patient and surgical characteristics. Using a database of more than 8 million patients per year, a weighted score was determined based on preoperative considerations and their impact on perioperative outcome measures: MCs, SCs, revisions, and mortality. This index represents an initial step in the clarification of anticipated risk that is intrinsic to surgical interventions in the cervical spine, and may eventually help quantify the relative risk in relation to expected benefits for patients undergoing these various treatments.

\section{References}

1. Cho SK, Egorova NN: The association between insurance status and complications, length of stay, and costs for pediatric idiopathic scoliosis. Spine (Phila Pa 1976) 40:247-256, 2015

2. Clevenger B, Richards T: Pre-operative anaemia. Anaesthesia 70 (Suppl 1):20-28, e6-e8, 2015

3. Diebo BG, Passias PG, Marascalchi BJ, Jalai CM, Worley NJ, Errico TJ, et al: Primary versus revision surgery in the setting of adult spinal deformity: a nationwide study on 10,912 patients. Spine (Phila Pa 1976) 40:1674-1680, 2015 
4. Eichholz KM, Ryken TC: Complications of revision spinal surgery. Neurosurg Focus 15(3):E1, 2003

5. Etame AB, Wang AC, Than KD, La Marca F, Park P: Outcomes after surgery for cervical spine deformity: review of the literature. Neurosurg Focus 28(3):E14, 2010

6. Furlan JC, Kalsi-Ryan S, Kailaya-Vasan A, Massicotte EM, Fehlings MG: Functional and clinical outcomes following surgical treatment in patients with cervical spondylotic myelopathy: a prospective study of 81 cases. J Neurosurg Spine 14:348-355, 2011

7. Halvorsen CM, Lied B, Harr ME, Rønning P, Sundseth J, Kolstad F, et al: Surgical mortality and complications leading to reoperation in 318 consecutive posterior decompressions for cervical spondylotic myelopathy. Acta Neurol Scand 123:358-365, 2011

8. Hart RA, Cabalo A, Bess S, Akbarnia BA, Boachie-Adjei O, Burton D, et al: Comparison of patient and surgeon perceptions of adverse events after adult spinal deformity surgery. Spine (Phila Pa 1976) 38:732-736, 2013

9. Hirpara KM, Butler JS, Dolan RT, O'Byrne JM, Poynton AR: Nonoperative modalities to treat symptomatic cervical spondylosis. Adv Orthop 2012:294857, 2012

10. Lawrence BD, Brodke DS: Posterior surgery for cervical myelopathy: indications, techniques, and outcomes. Orthop Clin North Am 43:29-40, vii-viii, 2012

11. Lovasi GS, Underhill LJ, Jack D, Richards C, Weiss C, Rundle A: At odds: concerns raised by using odds ratios for continuous or common dichotomous outcomes in research on physical activity and obesity. Open Epidemiol J 5:13-17, 2012

12. Lovecchio F, Hsu WK, Smith TR, Cybulski G, Kim B, Kim JYS: Predictors of thirty-day readmission after anterior cervical fusion. Spine (Phila Pa 1976) 39:127-133, 2014

13. Memtsoudis SG, Hughes A, Ma Y, Chiu YL, Sama AA, Girardi FP: Increased in-hospital complications after primary posterior versus primary anterior cervical fusion. Clin Orthop Relat Res 469:649-657, 2011

14. Menzin J, Zhang BZP: A health-economic assessment of cervical disc arthroplasty compared with allograft fusion. Tech Orthop 25:133-137, 2010

15. Nagashima H, Morio Y, Yamashita H, Yamane K, Teshima $\mathrm{R}$ : Clinical features and surgical outcomes of cervical myelopathy in the elderly. Clin Orthop Relat Res 444:140-145, 2006

16. Pumberger M, Chiu YL, Ma Y, Girardi FP, Vougioukas V, Memtsoudis SG: Perioperative mortality after lumbar spinal fusion surgery: an analysis of epidemiology and risk factors. Eur Spine J 21:1633-1639, 2012

17. Qureshi SA, McAnany S, Goz V, Koehler SM, Hecht AC: Cost-effectiveness analysis: comparing single-level cervical disc replacement and single-level anterior cervical discectomy and fusion: clinical article. J Neurosurg Spine 19:546554, 2013

18. Rao RD, Currier BL, Albert TJ, Bono CM, Marawar SV, Poelstra KA, et al: Degenerative cervical spondylosis: clinical syndromes, pathogenesis, and management. J Bone Joint Surg Am 89:1360-1378, 2007

19. Rihn JA, Harrod C, Albert TJ: Revision cervical spine surgery. Orthop Clin North Am 43:123-136, ix-x, 2012
20. Sampath P, Bendebba M, Davis JD, Ducker TB: Outcome of patients treated for cervical myelopathy. A prospective, multicenter study with independent clinical review. Spine (Phila Pa 1976) 25:670-676, 2000

21. Skolasky RL, Thorpe RJ Jr, Wegener ST, Riley LH III: Complications and mortality in cervical spine surgery: racial differences. Spine (Phila Pa 1976) 39:1506-1512, 2014

22. Smith JS, Saulle D, Chen CJ, Lenke LG, Polly DW Jr, Kasliwal MK, et al: Rates and causes of mortality associated with spine surgery based on 108,419 procedures: a review of the Scoliosis Research Society Morbidity and Mortality Database. Spine (Phila Pa 1976) 37:1975-1982, 2012

23. Tetreault LA, Kopjar B, Vaccaro A, Yoon ST, Arnold PM, Massicotte EM, et al: A clinical prediction model to determine outcomes in patients with cervical spondylotic myelopathy undergoing surgical treatment: data from the prospective, multi-center AOSpine North America study. J Bone Joint Surg Am 95:1659-1666, 2013

24. Todd AG: Cervical spine: degenerative conditions. Curr Rev Musculoskelet Med 4:168-174, 2011

25. Veeravagu A, Cole T, Jiang B, Ratliff JK: Revision rates and complication incidence in single- and multilevel anterior cervical discectomy and fusion procedures: an administrative database study. Spine J 14:1125-1131, 2014

26. Vincent GK, Velkoff VA: The Next Four Decades. The Older Population in the United States: 2010 to 2050. Population Estimates And Projections. Washington, DC: U.S. Census Bureau, 2010 (https://www.census.gov/ $\mathrm{prod} / 2010 \mathrm{pubs} / \mathrm{p} 25-1138 . p d f$ ) [Accessed May 3, 2017]

27. Worley N, Marascalchi B, Jalai CM, Yang S, Diebo B, Vira S, et al: Predictors of inpatient morbidity and mortality in adult spinal deformity surgery. Eur Spine J 25:819-827, 2016

\section{Disclosures}

Dr. Passias reports being a consultant to Medicrea and teaching an educational course for Zimmer Biomet. Dr. Lafage reports direct stock ownership in Nemaris Inc.; being a consultant for NuVasive; speaking/teaching arrangements with DePuy Spine, NuVasive, Medicrea, and MSD; and support of non-study-related clinical or research effort from DePuy Spine, NuVasive, Stryker, and $\mathrm{K} 2 \mathrm{M}$ (paid through ISSGF).

\section{Author Contributions}

Conception and design: Passias, Diebo, Lafage. Analysis and interpretation of data: Passias, Diebo, Lafage. Drafting the article: Passias, Jalai, Paltoo, Bono. Critically revising the article: Passias, Diebo, Marascalchi, Horn, Zhou, Paltoo, Worley, Poorman, Challier, Dixit, Paulino, Lafage. Reviewed submitted version of manuscript: all authors. Approved the final version of the manuscript on behalf of all authors: Passias. Statistical analysis: Diebo, Marascalchi, Jalai. Study supervision: Lafage.

\section{Correspondence}

Peter G. Passias, New York Spine Institute, NYU Langone Medical Center, Hospital for Joint Diseases, 301 East 17th St., New York, NY 10003. email: pgpassias@yahoo.com. 